\title{
EL FONDO ANGUSTIADO DE LOS \\ "NOCTURNOS" DE XAVIER VILLAURRUTIA
}

POR

\author{
MANUEL MARTIN-RODRIGUEZ \\ University of California, Santa Barbara
}

\begin{abstract}
Al lecr los "Nocturnos" de Xavier Villaurrutia, incluidos en las secciones "Nocturnos" y "Otros nocturnos" de su libro Nostalgia de la mucrle", términos como muerte, desamor, incomunicación, soledad o aislamicnto se van configurando $\mathrm{cn}$ la mente del lector como las claves para la comprensión del complejo mundo que hace de los "Nocturnos" una obra macstra de pocsía, marcada por la interpretación angustiada del pocta.

De todos esos clementos, la soledad es lo primero que nos llama la atención. En los "Nocturnos", la presencia humana se limita a la persona poética. Casi nunca aparecen los otros, cl clemento humano extcrior al sujeto. Para esta soledad, los críticos han propucsto diversas interpretaciones, casi todas basadas en la singularidad intelectual de Villaurrutia. Así, Giuseppe Bellini, basándose en El laberinto de la soledad de Octavio Paz, propone que la soledad en la obra de Villaurrutia responde a la necesidad del pocta de ser diferente y afirmar su diferencia en la soledad ${ }^{3}$.
\end{abstract}

Frank Dauster, por su parte, nos habla de una pérdida de concreción y de una confusión de sensaciones que representan en el autor de Nostalgia "the utter isolation into which he has been led by reason." (Dauster p. 48). La razón, según Dauster, llcva a Villaurrutia al solipsismo, al aislamicnto y a la soledad, por lo que

\footnotetext{
' Nostalgia de la muerte, nombrado a partir de ahora como Nostalgia, se publicó por primera vez en 1938. La versión definitiva es de 1946. Todas las citas de ese libro, así como de otros textos de Villaurrutia, se refieren a Obras. La página se indica entre paréntesis.

${ }^{2}$ El laberinto de la soledad no ha sido utilizado como referencia directa para este trabajo. Por tanto, todas las citas de Paz se refieren a Xavier Villaurrutia en persona y en obra. ${ }^{3}$ Una concepción muy similar sostiene Iraida Bustillo, basándose también en Octavio Paz. Para Bustillo, "la soledad se deriva de la ausencia de la muerte" (Bustillo p. 65), lo que determinaría el tratamiento onírico de la misma en la poesía de Villaurrutia.
} 
también Dauster interpreta la solcdad como voluntad de soledad por parte del pocta ${ }^{4}$.

Una tercera interpretación, de Eugene L. Morctta, ve la soledad y cl aislamicnto como cstados pasajeros, superables mediante un cjercicio de conciencia. Así, pucs, la atmósfera de los "Nocturnos" proporcionaría una especic de reducción esencial que facilitaría la percepción y aumentaría la "probabilidad de súbitas revclacioncs" (Moretta47). En otras palabras, scria "la cscenografía creada por el pocta para representar la soledad y $\mathrm{cl}$ desco de supcrarla buscando lo que pueda haber de real dentro del mundo que encicra a la conciencia" (Moretta 56).

Estas tres interpretaciones desatienden, sin embargo, clementos importantes de los textos en los que la soledad no es buscada por el yo poćtico, sino que se le va imponiendo imperecptiblemente hasta provocar una seric de desdoblamientos que acaban por cortar los lazos de la persona con el mundo exterior.

Numerosos motivos configuran cl mundo de la soledad en los "Noclurnos". Entre cllos, lo hucco se nos aparece como uno de los mås recurrentes. En cl "Nocturno amor", por cjemplo, cl cuerpo del amanie se percibe como un hueco (cs decir, como cl eco de una presencia):

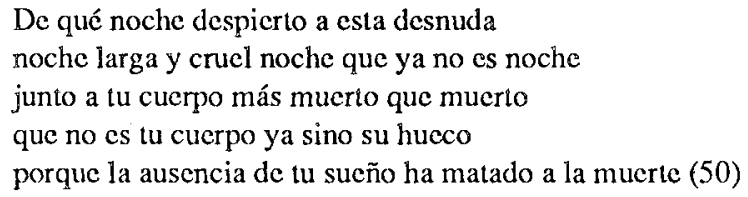

Es importante notar que, a través de lo hueco, la soledad se asocia con la mucrte. En cl "Nocturno amor" cscl cuerpo del amante cl que, por virtud del sucño, cstá "más mucrto que mucrto", pero posteriormente en la obra cs la mucrte misma la que llena ese hucco:

si la muerte hubiera venido aquí a New Haven escondida en un hueco de mi ropa en la maleta en el bolsillo de uno de mis trajes (p. 54).

\footnotetext{
${ }^{4}$ Esto está en consecuencia con una imprecisión de Dauster a la hora de diferenciar entre vida personal y obra literaria; imprecisión que matiza su interpretación de la relación entre ambas. Según Dauster, "about Xavier Villaurrutia's personal life there is a pervasive mystery, as though this enigmatic personality had deliberately cultivated as a mode of existence those preoccupations which lie at the core of his plays and poetry" (Dauster 17). Sería mas fácil pensar, sin embargo, que es la vida la que determina las obsesiones de la obra y ése es el enfoque que seguiremos en este trabajo.
} 
Así pucs, por medio de una reclaboración del motivo del hucco, Villaurrutia consigue involucrar muerte, sucño, soledad y ausencia en un supraconcepto de implicaciones importantes en el mundo de los "Nocturnos". En el "Nocturno amor", cste supraconcepto se apodera para siempre ya del plano erótico de la obra. Para cllo, la descripción del amante se sirve, una vez más, de las partes del cuerpo que denotan oquedad:

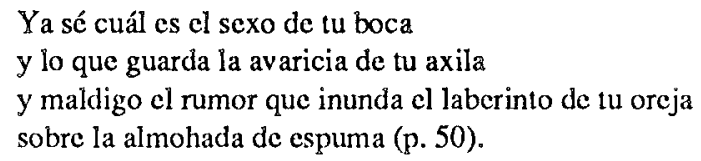

Boca, axila y laberinto de la orcja sirven, a la vez, para enlazar este tema con cl de la imposibilidad de comunicación del yo poćtico con cl mundo, como veremos más adclante, y son unas imágenes clocuentes de solcdad c introspección. Solcdad que se hace máxima en cl motivo de la pérdida de la propia sombra, como ocurrirá cn el "Nocturno grito": "tengo micdo de mi voz/ y busco mi sombra en vano" ( $p$. 46). Igual ocurrirá en cl "Nocturno sucño", en donde la noche, presencia amcnazante, trac consigo la soledad: "mc robó mi sombra/ la sombra cerrada (p. 48).

La pérdida de la sombra cs, además, la desaparición absoluta del otro, el símbolo clave del aislamientos. En este sentido, hay que matizar lo que hasta ahora venimos diciendo, puesto que en los "Nocturnos" la ausencia es a la vez presencia y ausencia. Se puede hablar, valga la paradoja, de presencia de la soledad, un cstado

${ }^{5} \mathrm{La}$ imagen de la pérdida de la sombra es una de las varias que Villaurrutia comparte con el Rafacl Alberti de Sobre los ángeles. En la obra de Alberti, en "El cuerpo deshabitado", encontramos:

\author{
Va muerto \\ Muerto, de pie, por las calles \\ ... \\ Sin ojos, sin voz, sin sombra. (76-77)
}

Véanse, también estos ejemplos: "pasaba un traje/ deshabitado, hueco" (76); "no es un hombre, es un boquetc/... un boquete, sin eco" (77). Particularmente interesante es cl verso "A sus pies, él mismo, sin vida" (133), que tiene su correlato en el "Nocturno sueño":

sin gota de sangre

sin ruido ni peso

a mis pies clavados

vino a dar mi cuerpo. (49) 
intermedio que, como nota Octavio Paz, "designa un momento đe extrema atención en el centro del abandono también más extremo: dormir con los ojos abicrtos, ver con los ojos ccrrados. El cstado intermedio tiene otro nombre: agonía. También se llama: duda" (Paz, 84). Un estado angustiado en el que la solcdad cxige la presencia clíptica del otro para ser soledad total: no la inexistencia del otro, sino su presencia invisible; no la mucrte cumplida, sino la muerte al acecho. Los otros y la mucrte crean un hucco en los "Nocturnos" que el poeta no es capaz de llenar. Más y mås, vemos que cl hucco se agranda, que lo domina todo, el amor y la mucrtc.

Así, los órganos del cuerpo se convierten en prisión del yo. En cl "Noclurno mucrto", la persona poćtica percibc un ruido, pero csc estímulo del mundo cxtcrior no sc interioriza, queda "preso cn cl caracol de mi orcja dormida" (p.52). Del mismo modo, las palabras se le ahogan entre los barrotes de los dientes en el "Nocturno amor": "y todas las palabras en la prisión de la boca" (p. 50).

Más aún, cuando la palabra sí llega a pronunciarse, cscapa al control de la voz poćtica, transformándose por si misma ante la angustia del yo:

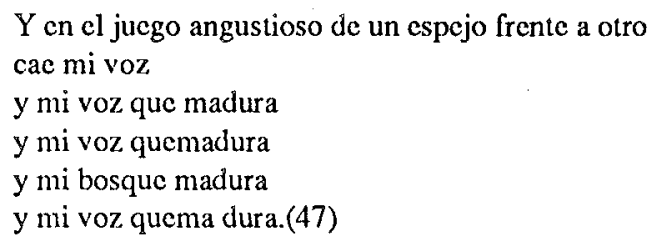

Hasta tal punto que la voz que prometía madurar (tal vez como anuncio de una futura comunicación) acaba por quemar "como cl hiclo de vidrio" (p.47), es decir, cl espejo que refleja al propio hablante ${ }^{6}$.

Comicnzan de cse modo los desdoblamientos de todo tipo: del yo con respecto al mundo y del yo con respecto a si mismo’. Estos desdoblamientos cstán tambićn regidos por la dialéctica presencia/ausencia y se concentran, sobre todo, en los motivos del cco y cl cspejo. El cco es y no es palabra, porque ha perdido su condición real para no scr más que una repctición, un rebotc, palabra errantc desasida ya de su cmisor. Del mismo modo, cl espejo funciona también como cco,

Aunque más que de influencias parece que se trata de coincidencias ambientales, propiciadas por la irrupción del surrealismo en las letras hispanas, el estudio de estas coincidencias está por hacerse y arrojaría una interesante luz sobre algunos de los puntos que aquí estamos tratando.

"Este pasaje ha sido comentado por el propio Villaurrutia en "La rosa de Cocteau" (923).

7 Ver Moretta, 127, para un análisis de los desdoblamientos. 
como la presencia de un reflejo y la ausencia de un cuerpo real (esto hace que $\mathrm{el}$ cucrpo, sobre todo el del yo poćtico, se aluda con frecuencia como "estatua"). El poema precisamente llamado "Nocturno de la estatua" es una serie de ecos en succsión de asociaciones metonímicas que configuran un círculo cerrado, un laberinto en el que la persona poćtica se pierde a un ritmo vertiginoso. Es una persecución furiosa sin salida que lleva desde lo real aparente (desde lo que se cree que es, y no es) hasta lo aparente real (lo que sólo es como representación de otra cosa):

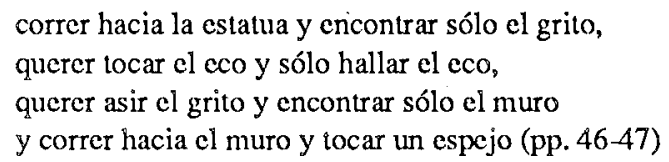

La persona, situada en frente del cspejo, se aterroriza ante su desdoblamiento; quicre hablar con su figura, pero cl cspcjo es un muro y su voz rebota como un grito, como el cco de un grito de terror ante sí mismo.

Se comprenderá mejor esie pocma atendiendo a su colocación en cl libro. Le precede cl "Nocturno grito", que anuncia la problemática de los desdoblamientos a través del motivo de la sombra:

¿scrá mía aquella sombra

sin cuerpo que va pasando?

¿Y mía la voz perdida

que va la calle incendiando? (p. 46)

Viene a continuación el "Nocturno de la estatua", que acabamos de ver, como cxperiencia traumática de imposibilidad de reunificación (cuando, en cl pocma, la persona cncuentra a la estatua, hacia cl final, la estatua le contesta que está muerta de sucño). No es de extrañar que a dicha experiencia le siga en cl pocmario $\mathrm{cl}$ "Nocturno en que nada se oye". La soledad es definitiva. El yo no se pucde comunicar. Las palabras se convicrten en gritos inasibles. La desolación se hace silencio. No se cncontrará otra referencia a la voz en los títulos hasta ocho poemas más tardc. Mientras tanto, Villaurrutia coloca versos como cl inicial de "Nocturno amor": "El que nada se oye en csta alberca de sombra" (p. 49). O cl balbucco del "Nocturno cicrno" "cuando la vi cuando la vid cuando la vida" (51) $\mathrm{cn} \mathrm{cl}$ que $\mathrm{cl}$ pocta confirma su silencio:

o cuando todo ha muerto tan dura y lentamente que da miedo alzar la voz y preguntar "quién vive" 


\author{
dudo si responder \\ a la muda pregunta con un grito \\ por temor de saber que ya no existo. (p. 51-52)
}

Es el estupor, la duda máxima, la convicción de que todo conocimiento es imposible; es "cl latido de un mar en el que no sé nada" (47).

El silencio presagia la mucrte. Por eso es que la siguiente referencia a la voz en un tílulo se da en el "Nocturno en que habla la muerte". En este poema el desdoblamiento de la persona llega a su punto álgido al descubrir que su otro yo no está mucrto sino que es, propiamente, la mucric, que mediatiza sus palabras:

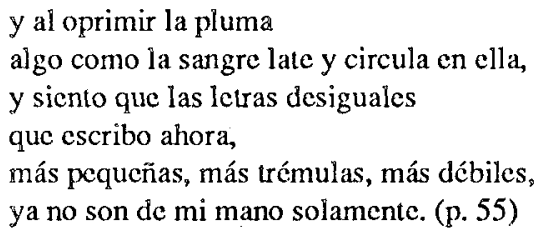

Hasta aquí hemos venido analizando cómo la soledad, la incomunicación, el silencio y la muerte constituyen el transfondo angustiado de los "Nocturnos". Cabe preguntarse ahora por qué se da ese trasfondo, rastreando una vez más los texios para encontrar motivos conscientes o inconscientes (recuérdese cl papel fundamental del sucño cn la pocsía de Villaurrutia) que nos lo pucdan aciarar.

Una de csas claves nos la proporciona el motivo del naufragio, asociado con cl más amplio del mar. En cl "Nocturno" que abre la sccción "Otros nocturnos" renemos una de las apariciones del motivo del naufragio:

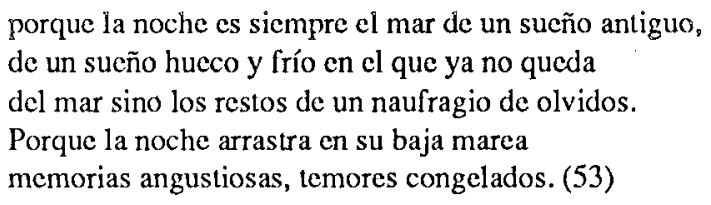

¿Qué son csas "memorias angustiosas"? Tal vez la siguiente observación de Paz nos pucda ayudar a aclararlo: "Niños, habían presenciado las violencias y las matanzas revolucionarias; jóvenes, habían sido testigos de la rápida corrupción de los revolucionarios y su transformación cn una plutocracia ávida y zafia". (Paz, 22) Siguiendo ese razonamiento, no parece violentar el texto la interpretación de que "los restos de un naufragio" reficre a su condición de miembro de "una de las clases más afectadas por la Revolución, la media alaa, que fue desalojada de sus 
posesiones y de sus prebendas", (González Casanova 17) y que las "memorias angustiosas" son sus recuerdos de la época sangrienta de la revolución.

Aún hay más. Al terreno social hay que sumar una experiencia personal insatisfactoria que marca para siempre su rclación consigo mismo y con cl mundo. Es una relación edipal con su madre, expresada también mediante el motivo del mar y presente en el "Nocturno mar":

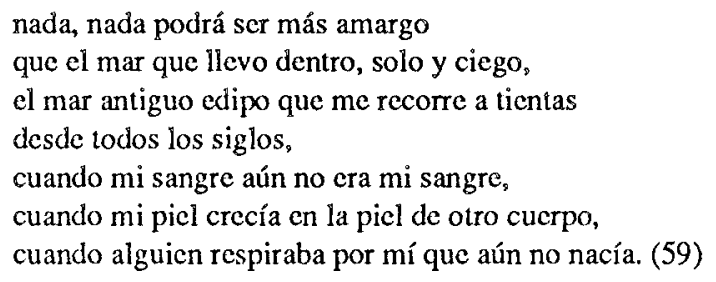

La relación con cl otro ha sido insatisfactoria, pues, desde el momento de su concepción, y la incomunicación será rctomada cn cl pocma dos csirofas más tarde:

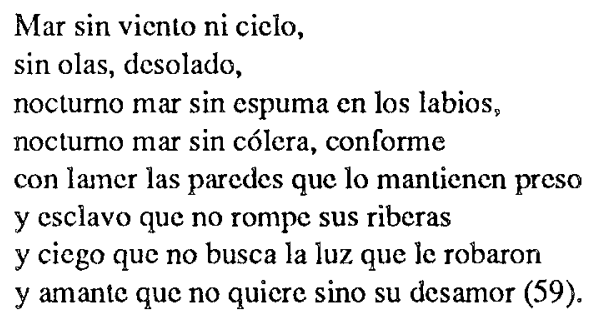

Su amargo rencor es todavía más claro en la siguiente estrofa; una vez más, rencor de haber nacido:

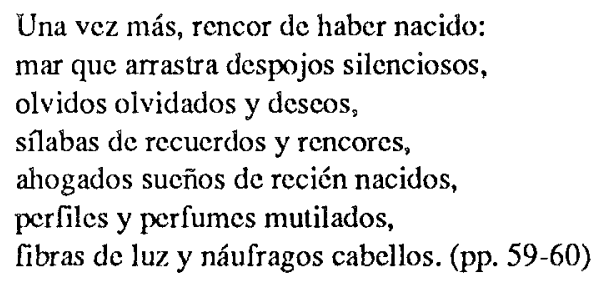

"Ahogados sucños" scría cl complemento personal de los "temores congelados" ya vistos, del mismo modo que los "despojos silenciosos" lo serían de los "restos del naufragio". Es cl desarraigo, en suma, que venimos detectando y que 
producirá una actitud ante el mundo no sólo inhibida (como se vio supra supra), sino también defensiva. El sueño y el silencio se asocian a menudo con el crimen, y el lugar de ese crimen es la calle. Para entender la importancia de la calle en este contexto es necesario primero considerar el papel de la alcoba, puesto que la alcoba es el lugar predominante de la acción de los "Nocturnos". La alcoba es una traslación metafórica del vientre materno y, por su oquedad, participa de las ideas de soledad y mucrte, como en cl "Nociurno de la alcoba": "La muerte toma siempre la forma de la alcoba que nos contiene". Y el poeta la define en el verso siguiente como "cóncava" (p. 60)

Participa de la mucrte, decimos, pero de la mucrie-compañera del "Nociurno en que habla la mucrte". Como oposición, está la mucrte temible, inesperada que ocurre cn la calle. Así, la calle cs cl lugar inhóspito por definición y se caractcriza como silenciosa, con cl silencio que precede al crimen (en el "Nocturno en que nada se oye"). Es en el "Nocturno sucño" donde encontramos mejor desarrollada la imagen de la calle. Ahí, la calle es el lugar del desdoblamiento: "oí que mis pasos/ pasaban ${ }^{8}$ (p. 48). Posteriormente, cs tambićn escenario de un crimen singular en cl que una mitad de ese ser desdoblado da muerte a la otra, en un mecanismo de auto-castigo que nos revela un comportamicnto culposo, probablemente motivado por $\mathrm{cl} \mathrm{amor/rencor} \mathrm{hacia} \mathrm{la} \mathrm{imagen} \mathrm{de} \mathrm{la} \mathrm{madre} \mathrm{que} \mathrm{lo} \mathrm{abandona} \mathrm{náufrago} \mathrm{cn} \mathrm{cl}$ mundo:

\author{
y al doblar la esquina \\ un segundo largo \\ mi mano accrada \\ encontró mi espalda. (pp. 48-49)
}

Las presiones tanto de la historia social como personal son, a nuestro entender, las que determinan la angustia y el desasosiego subyacentes a los "Nocturnos". Para confirmarlo, resulta interesante obscrvar cl "Nocturno de Los Angelcs", cl único "Nocturno" de tono humorístico y relajado. La calle en Los Angeles, picrde por completo su carácter amenazante, como si la distancia física se hicicra también

\footnotetext{
${ }^{8}$ La actitud defensiva ante el mundo se observa también en su actitud hacia los objetos, actitud que se resume en su obra Invitación a la muerte en los siguientes términos: "Porque las cosas que nos rodean ... acaban por perder el objeto inocente para el que fueron creadas y nos ofrecen, en cambio, una vida servil de esclavos, de cómplices. Un espejo acaba por ser útil solamente para que veas, sin volver la cabeza, lo que pasa a tu espalda" (378). ${ }^{9}$ Otro ejemplo de mecanismo de auto-castigo es el verso " $y$ amante que no quicre sino su desamor" (59).
} 
espiritual. El poema se abre con el verso "se diria que las calles fluyen dulcemente en la noche" (p. 55), que contrasta fucrtemente con lo anterior. Los seres que pucblan esta calle no se atacan ni son proyecciones de la persona poética, sino que "cambian miradas, atreven sonrisas,/ forman imprevistas parejas". Son los ángcles, hombres asćpticos con nombres asćpticos y "divinamente sencillos./ $\mathrm{Sc}$ llaman Dick, o John, o Marvin o Louis". (p. 56)

José Joaquín Blanco, basándose en las cartas de Villaurrutia a Novo, apunta que cl viaje a los Estados Unidos fuc para el pocta una libcración. (Blanco, p. 184). Libcración de la memoria, de la historia y hasta del tormento de la introspección. En cl pocma sobre los ángeles, la voz sc hacc narrativa, no inquisitiva ${ }^{10}$.

El amor cscindido, cl trauma del nacimiento (el mar) y la relación con la madre, encuentran también en el "Nocturno de Los Angeles" utópica solución:
si cada uno dijera en un momento dado, en sólo una palabra, lo que piensa, las cinco letras del DESEO formarían una enorme cicatriz luminosa, una constelación más antigua, más viva aún que las otras.
Y esa constelación sería como un ardiente sexo en el profundo cuerpo de la noche, o, mejor, como los Gemelos que por primera vez en la vida se miraran de frente, a los ojos, y se abrazaran ya para siempre. (p. 55)

Es cl reino milenario, la superación de los desdoblamientos que se observan en el resto de los pocmas, superación anhelada, ansia de comunión, no đe soledad como quería Bellini".

En conclusión, en los "Nocturnos", de Xavier Villaurrutia se reflcja cl íntimo desajuste del pocta con su vida y su cra, y cl atormentado testimonio de una de esas luchas internas por recupcrar la unidad que tanto caractcrizan a la pocsía del siglo XX. En palabras de Juan García Ponce, la obra de Villaurrutia es un diario intimo cn cl que cl artista ha grabado poco a poco su rclación con cl mundo" (García Ponce p. 35). Y tambićn consigo mismo, añadiriamos nosotros. Una relación atormentada que dio como resultado algunos de los mejores pocmas en español de este siglo.

\footnotetext{
${ }^{10}$ Blanco habla de que esa liberación se observa en toda la sección "Otros nocturnos", pero crecmos que sólo es observable en el "Nocturno de Los Angeles".

${ }^{11}$ El tema de los gemelos es un tema recurrente en la literatura de la época. Una expresión señera sería la obra de Robert Musil, El hombre sin atributos, especialmente el volumen IV. Próxima en tiempo a la obra de Villaurrutia, se trata de otra interesante coincidencia ambiental.
} 


\section{OBRAS CITADAS}

Alberti, Rafacl. Sobre los ángeles. Yo era un tonto y lo que he visto me ha hecho dos tontos. 1929. Ed. C. Brian Morris. Madrid: Cátedra.

Bcllini, Giuscppe. "La pocsía de Xavier Villaurrutia". Letterature moderne, 10 (1960), 20-27.

Blanco, Josć Joaquín. La paja en el ojo ajeno: Ensayos de crítica. Pucbla: Universidad Autónoma de Pucbla, 1980.

Bustillo, Iraida. "Mucrte y solcdad en la poćtica de Xavicr Villaurrutia". Románica, 13 (1976): 65-76.

Dauster, Frank. Xavier Villaurrutia. New York: Twayne, 1971.

García Ponce, Juan. Cinco ensayos. Guanajuato: Universidad de Guanajuato, 1969.

González Casanova, Henrique. "Rescña de la pocsía mexicana del siglo XX." México en el arte 10-11 (1950): 11-22.

Morctta, Eugenc L. La poesia de Xavier Villaurrutia. México: Fondo de Cultura Económica, 1976.

Musil, Robert. El hombre sin atributos. Vol. IV. Barcclona: Scix Barral, 1984.

Paz, Octavio. El laberinto de la soledad. México: Fondo de Cultura Económica, 1959.

- Xavier Villaurrutia en persona y en obra. México: Fondo de Cultura Económica, 1978.

Villaurrutia, Xavicr. Obras. 1953. Ed. Alí Chumacero ct al. México: Fondo de Cultura Económica, 1966. 